\title{
Late reoperations after repaired acute type A aortic dissection
}

\author{
Reinhard Kobuch, MD, ${ }^{\mathrm{a}}$ Michael Hilker, MD, ${ }^{\mathrm{a}}$ Leopold Rupprecht, MD, ${ }^{\mathrm{a}}$ Stephan Hirt, MD, ${ }^{\mathrm{a}}$ \\ Andreas Keyser, MD, ${ }^{\mathrm{a}}$ Thomas Puehler, MD, ${ }^{\mathrm{a}}$ Matthias Amman, MD, ${ }^{\mathrm{b}}$ Wolfgang Zink, MD, ${ }^{\mathrm{b}}$ and \\ Christof Schmid, MD
}

\begin{abstract}
Objective: Late complications can develop in patients after surgery for aortic type A dissection, mandating redo surgery on the ascending aorta and arch.
\end{abstract}

\begin{abstract}
Methods: From 2006 to 2010, 23 patients (aged 41-69 years) who had late complications related to previous aortic surgery for acute type A dissection underwent redo surgery. Initial surgery included ascending aorta replacement in all cases.
\end{abstract}

\begin{abstract}
Results: The main indications for reoperation were progressive enlargement of the false lumen of the aortic arch or descending aorta and suture line dehiscence in 10 patients each. All patients with progressive aneurysm formation in nonresected aortic segments had persistent dissection within the aortic arch since initial surgery. Suture line dehiscence led to a localized hematoma in most cases. Three patients presented with graft infection and extensive perigraft hematoma. The average time interval from the initial repair to the redo procedure was $71 \pm 56$ months. Exchange of the formerly implanted Dacron graft in the ascending aorta was the most frequently used surgical procedure. Implantation of a valved conduit was deemed necessary in 4 cases, and isolated aortic valve replacement was necessary in 2 cases. A hybrid stent graft was used in 6 patients. All patients survived surgery, and 1 patient died of postoperative low output cardiac failure in hospital. Only 1 major stroke was noted.
\end{abstract}

Conclusions: Complex reoperations for repaired acute type A dissection can be performed safely. The concern for the reoperative risk should not dictate the operative strategy during the initial procedure in acute type A dissection. (J Thorac Cardiovasc Surg 2012;144:300-7)

The development of type A aortic dissection (ie, involving the ascending aorta or aortic arch) is a life-threatening disease with a high mortality rate if left untreated. A mortality of $1 \%$ per hour and an expected mortality of $70 \%$ to $90 \%$ during the first 3 months have been reported. ${ }^{1}$ More recently, results have improved with advances in diagnosis, better surgical techniques, and modern intensive care unit care. ${ }^{2}$ Therapy of choice usually consists of replacement of that part of the ascending aorta, which has a tear in the endothelial layer and involves the aortic arch in approximately half of the patients. ${ }^{3}$ The average 30-day mortality in Germany is reported to be $18.5 \%{ }^{3}$

Despite successful emergency surgery and uneventful recovery, many patients are far from being definitely cured. Regardless of the surgical techniques used, diseased aortic tissue is left in situ, which may become the source of late complications. The most susceptible region with regard to

From the Departments of Cardiothoracic Surgery ${ }^{\mathrm{a}}$ and Anesthesiology, ${ }^{\mathrm{b}}$ University Medical Center, Regensburg, Germany.

Disclosures: Authors have nothing to disclose with regard to commercial support. Received for publication Dec 2, 2010; revisions received July 15, 2011; accepted for publication Aug 25, 2011; available ahead of print Nov 14, 2011.

Address for reprints: Christof Schmid, MD, Department of Cardiothoracic Surgery,

Franz-Josef-Strauss-Allee 11, University Medical Center, 93053 Regensburg,

Germany (E-mail: christof.schmid@klinik.uni-regensburg.de).

$0022-5223 / \$ 36.00$

Copyright (c) 2012 by The American Association for Thoracic Surgery

doi:10.1016/j.jtcvs.2011.08.052 postsurgical adverse sequelae is the aortic arch. Up to $43 \%$ of patients demonstrate persistent dissection in a previously not replaced aortic arch. ${ }^{4}$ As a consequence, $10 \%$ to $27 \%$ of patients experience a late increase of the false lumen, which may cause pain or rupture. ${ }^{5}$ Further problems include the formation of pseudoaneurysms at the suture lines and valvular incompetence of the aortic root. ${ }^{6,7}$

We analyzed our patient cohort with residual or recurrent aortic disease of type A dissection mandating redo surgery on the ascending aorta and arch.

\section{PATIENTS AND METHODS \\ Patient Data}

From 1998 to October 2010, 228 patients underwent aortic surgery for acute type A dissection at the University Medical Center. Diagnosis was established on the basis of preoperative computed tomography (CT) or echocardiography. Because most of the patients live in a rural countryside and usually consult a physician rather late despite being burdened with numerous general risk factors, including obesity, hypertension, and diabetes, the primary surgical strategy was to achieve patient survival and not to perform aggressive aortic arch replacement. The aortic valve was preserved in $87 \%$ of cases (ie, whenever possible).

A survey of our aortic surgery database revealed 23 patients with late complications related to previous aortic surgery for acute aortic type A dissection during follow-up and mandating redo aortic surgery. There were 19 male and 4 female patients aged 41 to 69 years (mean, $56 \pm 8$ years). Some $74 \%$ of patients had a body mass index above normal levels (mean, $27 \pm$ 3.2). The prevalence of cardiovascular risk factors was low except for arterial hypertension, which was also seen in $74 \%$ of patients (Table 1). The actual mean European System for Cardiac Operative Risk Evaluation was $13 \pm 9$. 


\section{Abbreviations and Acronyms \\ $\mathrm{CT}=$ computed tomography \\ GRFG $=$ gelatin-resorcinol-formaldehyde- glutaraldehyde}

\section{Primary Surgical Procedures}

After acute type A dissection, most patients underwent replacement of the ascending aorta with or without aortic valve resuspension or replacement, and an open distal anastomosis with or without hemiarch replacement during hypothermic circulatory arrest and antegrade cerebral perfusion. The false lumen of the aorta was mostly obliterated with gelatin-resorcinol-formaldehyde-glutaraldehyde (GRFG) biologic glue; far less often it was sutured with Teflon felt as abutment. The anastomoses between the Dacron prosthesis and the aortic wall were performed with monofilament running sutures. A mechanical valve conduit was used in 5 patients, and the Yacoub technique was used in 1 patient. A separate aortic valve replacement was performed in 1 patient. Aortic arch surgery was performed in 5 patients, 3 of whom had a hemiarch procedure. An elephant trunk was performed in 1 patient (Figure 1). Transesophageal echocardiography was routinely used to control for residual flow in the false lumen of the aortic arch and descending aorta. A significant flow was not seen in the false lumen, neither antegrade nor retrograde, in any patient. After recovery and discharge, all patients were scheduled for regular follow-up CT scans at the outpatient clinic of University Medical Center. After the initial procedure, 5 patients had undergone further procedures during consecutive hospital stays (Table 2).

\section{Aortic Redo Procedures}

Reoperation for development of progressive false aneurysm, enlargement of a persistently perfused false lumen, and graft infection followed the same surgical principles compared with the initial surgical procedure. The arterial access was at the surgeon's discretion, but prophylactic cannulation of the femoral artery was preferred in emergency cases with extensive substernal bleeding, that is, ruptured aneurysm or suture line failure (Table 2). The venous line was inserted into the right atrium except for (expected) uncontrollable bleeding after sternotomy. After the onset of extracorporeal circulation, deep hypothermia $\left(20^{\circ} \mathrm{C}\right.$ in tympanum and bladder $)$ was initiated if aortic arch repair was intended. Near-infrared spectroscopy was used for cerebral monitoring. Otherwise, only mild to moderate hypothermia was induced $\left(28^{\circ} \mathrm{C}-32^{\circ} \mathrm{C}\right)$.

The surgical techniques were adapted to the patient's aortic pathology, but the ascending aorta/aortic root was always operated first and the aortic arch was operated last. An aortic root replacement was performed using standard techniques. Mechanical valved conduits were obtained from Carbomedics (Sorin Inc, Austin, Tex). Biological valved conduits were custom-made by inserting a Perimount valve (Baxter Healthcare Corporation CardioVascular Group, Irvine, Calif) into an appropriately sized Dacron tubular graft. For arch repair or replacement, continuous cerebral perfusion was granted by maintaining a flow of 0.5 to $1.0 \mathrm{~L} / \mathrm{min}$ via the arterial cannula in the right subclavian artery, simultaneously clamping the brachiocephalic trunk and the left carotid artery, or by inserting 2 inflatable balloon catheters into the orifices of the carotid vessels. The frozen elephant trunk technique included transecting the aorta distal to the offspring of the left subclavian artery, inserting the Evita open hybrid stent graft (Jotec GmbH, Hechingen, Germany) guided by a femorally advanced guide wire and transesophageal echocardiography into the true lumen, deploying the covered stent $(14 \mathrm{~cm}$ in length), suturing the prosthesis to the wall of the proximal end of the descending aorta, and reinserting the head vessels into the Dacron graft. ${ }^{8,9}$ Because preoperative sizing for the stent graft prosthesis was difficult, especially in case of partial or complete thrombotic obliteration of the false lumen, definitive sizing was accomplished during visual inspection of the true lumen of the descending aorta. For a conventional elephant trunk prosthesis, the tubular Dacron graft was fixed to allow 6 to $8 \mathrm{~cm}$ of the distal end floating in the descending aorta (Table 3).

\section{Statistical Analysis}

All patient data were prospectively collected in the institutional database during the regular follow-ups. Patient surveillance visits, including CT controls, were scheduled at 4, 10, 22, 34, 52, and 70 months, and then biannually. Follow-up was $100 \%$ complete. Statistical analysis was performed using the Statistical Package for the Social Sciences 16.0 software (SPSS, Chicago, Ill). Continuous data were calculated as a mean \pm standard deviation; categoric variables were displayed as frequency distributions (n) and simple percentages (\%).

\section{RESULTS}

\section{Indications for Redo Surgery}

The main indications for reoperation were progressive or symptomatic enlargement of the false lumen of the aortic arch or descending aorta and suture line dehiscence in 10 patients each $(43 \%)$. A diameter exceeding $6 \mathrm{~cm}$ was considered an indication for surgery regardless of symptoms. Asymptomatic patients were scheduled for surgery if aortic enlargement was $1 \mathrm{~cm}$ or more per year.

All patients with progressive aneurysm formation in nonresected aortic segments had persistent dissection within the aortic arch since the initial surgery. The proximal descending aorta directly after the orifice of left subclavian artery was most often affected. Of note, there was no continuous increase in aortic diameter after primary surgery. Instead, aortic growth started only 1 to 3 years before redo surgery in most cases.

Suture line dehiscence developed at proximal or distal suture lines or coronary buttons and led to a localized hematoma (false aneurysm) contained by ubiquitous adhesions in most cases (70\%). These patients remained hemodynamically stable and were able to undergo operation on an elective or urgent basis $(78 \%)$. Five patients underwent emergency redo surgery (22\%), 3 of whom presented with suture line dehiscence due to graft infection and extensive perigraft hematoma $(30 \%)$ reaching the backside of the sternum (Figure 2). The other 2 patients had aortic arch rupture (distal suture line) with severe cardiovascular compromise.

An aneurysmal aortic root with valvular incompetence was noted in only 2 patients. Secondary tissue necrosis and redissection, which has been attributed to the use of GRFG glue, was not present.

The time interval from the initial repair after acute type A aortic dissection to the redo procedure varied from 3 to 214 months, with a mean of $71 \pm 56$ months (median, 75 months) (Table 1).

\section{Surgical Procedures}

Exchange or (partial) replacement of the formerly implanted Dacron graft in the ascending aorta was the most 
TABLE 1. Patient characteristics

\begin{tabular}{lcr}
\hline & No. of patients & $\%$ \\
\hline Age & $56 \pm 8$ y & \\
Sex & 19 male, 4 female & \\
BMI & $27 \pm 3.2$ & \\
Hypertension & 17 & 74 \\
Coronary artery disease & 3 & 13 \\
Peripheral vascular disease & 1 & 4 \\
COPD & 1 & 4 \\
Diabetes & 1 & 4 \\
Prior cerebrovascular disease & 3 & 13 \\
Kidney dysfunction & 3 & 13 \\
Prior sternotomy & 23 & 100 \\
\hline$B M I$, Body mass index; COPD, chronic obstructive pulmonary disease.
\end{tabular}

frequently used surgical procedure $(n=15,65 \%)$. Implantation of a valved conduit was deemed necessary in 4 patients, and isolated aortic valve replacement was necessary in 2 patients. The need to extend the aortic procedure toward a hemiarch replacement was necessary in 5 patients, and a total arch replacement was indicated in 11 patients $(48 \%)$. In 6 of the latter patients, the Evita open hybrid stent graft was used, that is, a covered stent was used in the descending aorta. Separate covered aortic stents were inserted in an antegrade fashion via a side-arm of the arch prosthesis during reperfusion in 2 cases. In the 3 patients with (suspected) graft infection, extensive mediastinal irrigation was performed, but no omental or muscle flap transfer.

Arterial cannulation was achieved via the femoral or subclavian artery in 8 patients each, and direct aortic cannulation was possible in 7 patients. Extracorporeal circulation time ranged from 61 to 385 minutes (198 \pm 81 minutes), and crossclamp time ranged from 36 to 215 minutes (113 \pm 53 minutes). Deep hypothermic circulatory arrest was necessary in 19 patients $(83 \%)$, lasting 19 to 103 minutes ( $60 \pm 25$ minutes), and selective cerebral perfusion was carried out for 17 to 99 minutes ( $46 \pm 25$ minutes) (Table 2).

\section{Survival and Complications}

All patients survived surgery, and 1 patient died of postoperative low output cardiac failure in-hospital; thus, the success rate was $96 \%$. Postoperative drainage losses ranged from 100 to $3900 \mathrm{~mL}$ (mean $1300 \pm 1100 \mathrm{~mL}$ ). Redo sternotomy for suspected or manifest bleeding was performed in 5 patients. Extubation was achieved after 4 to 1300 hours (median 36 hours). Two patients required tracheostomy for prolonged mechanical ventilation. Only 1 major stroke with incomplete resolution of symptoms was noted after surgery. Vocal chord palsy was observed in 6 patients. Acute kidney failure necessitating temporary hemodialysis developed in 3 patients.

Patients remained in the intensive care unit for 2 to 53 days (median, 8 days) and were discharged after 5 to 57 days (median, 15 days). All patients except 2 could be

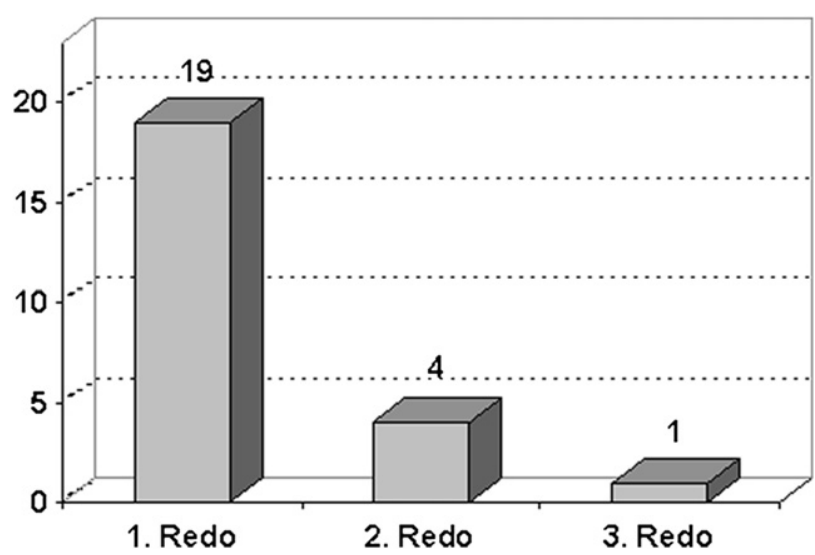

FIGURE 1. Number of redo procedures.

successfully rehabilitated to New York Heart Association I or II. Two patients required prolonged care for severe heart failure and multimorbidity, respectively (Table 4).

In the long-term follow-up, all patients are still alive and demonstrated complete thrombosis/obliteration of the false lumen, and aortic diameters remained stable (Figure 2). Further aortic interventions were necessary in 2 patients. Patient 13 had severe graft infection and first underwent redo replacement of the ascending aorta for suture line rupture; 17 months later, this patient underwent a second redo operation with re-replacement of the ascending aorta and arch for a further rupture of the ascending aorta (Figure 3). Patient 10, who had a stent fixed to the elephant trunk of the descending aorta, required revision of the stent.

\section{DISCUSSION}

Optimal surgery for acute type A aortic dissection is still a matter of debate. There are several surgical approaches to the problem, all of which are associated with instrinsic difficulties. In the United States and Europe, where the patients are more obese, many surgeons favor limited surgery with reconstruction of the aortic arch under the premise "survival first," whereas in Asia, with its smaller people, a more comprehensive surgical technique also regularly replacing the aortic arch is dominant. In the presented patient cohort, less extended surgery with preservation of the aortic arch was performed if the entry of the dissection was located in the ascending aorta, that is, the endothelial layer of the arch was intact. The dissected layers of the aortic arch (and aortic root) were approximated with Teflon-felt reinforced continuous sutures or GRFG glue. These 2 technical variants are wellestablished surgical procedures, but the question remains as to how the repaired aortic arch performs in the long-term.

Our patients were regularly seen on an outpatient basis with repetitive CT scans following a standardized followup protocol. During the follow-up, different pathologies developed necessitating redo aortic surgery: (1) Progressive dilatation of the dissected remaining native aorta, 
TABLE 2. Initial aortic procedure and indication for redo surgery

\begin{tabular}{|c|c|c|c|c|c|c|}
\hline No. & $\begin{array}{c}\text { Initial aortic } \\
\text { procedure }\end{array}$ & $\begin{array}{c}\text { Consecutive } \\
\text { cardiovascular } \\
\text { procedures } \\
\end{array}$ & $\begin{array}{c}\text { Time interval to } \\
\text { redo surgery (mo) }\end{array}$ & $\begin{array}{c}\text { Aneurysm } \\
\text { size }(\mathbf{m m}) \\
\end{array}$ & Indication for redo surgery & euroSCORE \\
\hline 1 & AAR & & 3 & 30 & Graft infection + endocarditis & 36.0 \\
\hline 2 & AAR & & 3 & 32 & Graft infection & 4.6 \\
\hline 3 & AAR & & 97 & 70 & $\begin{array}{l}\text { Descending aorta suture line } \\
\text { dehiscence }\end{array}$ & 7.1 \\
\hline 4 & AAR & CABG & 84 & 44 & $\begin{array}{l}\text { Graft infection }+ \text { AA suture line } \\
\text { dehiscence }\end{array}$ & 13.0 \\
\hline 5 & MCT & & 108 & 70 & $\begin{array}{l}\text { Progressive false lumen/arch } \\
\text { aneurysm }\end{array}$ & 7.2 \\
\hline 6 & AAR & & 114 & 61 & $\begin{array}{l}\text { Progressive false lumen/arch }+ \\
\text { aortic root aneurysm }\end{array}$ & 23.5 \\
\hline 7 & $\mathrm{AAR}+\mathrm{HAR}$ & & 17 & 60 & $\begin{array}{l}\text { Progressive false lumen/arch } \\
\text { aneurysm }\end{array}$ & 7.1 \\
\hline 8 & AAR & & 3 & 53 & $\begin{array}{l}\text { Progressive false lumen/arch } \\
\text { aneurysm and descending aorta }\end{array}$ & 7.1 \\
\hline 9 & MCT & & 69 & 72 & $\begin{array}{l}\text { Progressive false lumen/arch } \\
\text { aneurysm and descending aorta }\end{array}$ & 30.6 \\
\hline 10 & $\mathrm{AAR}+\mathrm{ArchR}+\mathrm{ET}$ & & 5 & 77 & $\begin{array}{l}\text { Progressive false lumen/arch } \\
\text { aneurysm and descending aorta }\end{array}$ & 1.7 \\
\hline 11 & AAR & & 2 & 76 & $\begin{array}{l}\text { Graft infection }+ \text { AA suture line } \\
\text { dehiscence }\end{array}$ & 10.0 \\
\hline 12 & Yacoub repair & AVR & 87 & 66 & $\begin{array}{l}\text { Progressive false lumen/arch } \\
\text { aneurysm and descending aorta }\end{array}$ & 4.5 \\
\hline 13 & $\mathrm{AAR}+\mathrm{AVR}$ & $\begin{array}{l}\text { Redo archR }+ \text { stent graft } \\
\text { descending aorta }\end{array}$ & $30 / 47$ & 46 & $\begin{array}{l}\text { Graft infection }+ \text { AA suture line } \\
\text { dehiscence }\end{array}$ & 14.5 \\
\hline 14 & MCT & & 96 & 58 & AA suture line dehiscence & 32.5 \\
\hline 15 & AAR & & 214 & 58 & AA suture line dehiscence & 7.5 \\
\hline 16 & $\mathrm{AAR}+\mathrm{AVR}+\mathrm{ArchR}$ & $\begin{array}{l}\text { Patch repair distal } \\
\text { arch }\end{array}$ & 32 & 100 & $\begin{array}{l}\text { Aortic arch/descending suture } \\
\text { line dehiscence }\end{array}$ & 14.5 \\
\hline 17 & AAR & & 173 & 78 & AA suture line dehiscence & 4.1 \\
\hline 18 & MCT & & 117 & 66 & Aortic arch suture line dehiscence & 10.4 \\
\hline 19 & $\mathrm{AAR}+\mathrm{HAR}$ & $\begin{array}{l}\text { Stent graft descending } \\
\text { aorta }\end{array}$ & 65 & 67 & $\begin{array}{l}\text { Progressive false lumen/arch } \\
\text { aneurysm and descending } \\
\text { aorta, AV incompetence, CAD }\end{array}$ & 9.1 \\
\hline 20 & AAR & & 12 & 58 & AA suture line dehiscence & 10.3 \\
\hline 21 & AAR & & 100 & 54 & Aortic arch suture line dehiscence & 11.2 \\
\hline 22 & $\mathrm{AAR}+\mathrm{HAR}$ & & 79 & 63 & $\begin{array}{l}\text { Progressive false lumen } \\
\text { descending aorta }\end{array}$ & 12.9 \\
\hline 23 & MCT & & 71 & 62 & $\begin{array}{l}\text { Progressive false lumen/arch } \\
\text { aneurysm }\end{array}$ & 18.5 \\
\hline
\end{tabular}

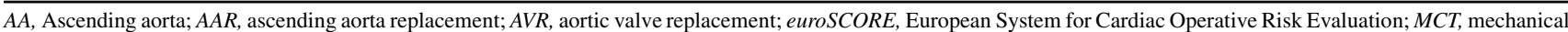
valved conduit; $H A R$, hemiarch replacement; $A r c h R$, total aortic arch replacement; $E T$, elephant trunk; $C A B G$, coronary artery bypass grafting.

predominantly of the false lumen, was seen in $43 \%$ of patients. The false lumen usually is fed antegradely, that is, immediately at the distal anastomotic line of the implanted prosthesis. The antegrade flow constantly exposes the weakened aortic wall to the high systemic blood pressure, ultimately widening the wall. A remarkable observation was that the dimensions of the dissected native aorta may remain constant for years and then increase for no obvious reason, perhaps triggered by hypertonic episodes. (2) Suture line ruptures were as frequent as the false lumen enlargement. These late complications are well known from aortic surgery and not limited to patients with aortic dissection. ${ }^{10}$ Especially in patients with aortic root replacement, the coronary buttons may tear off with time..$^{11}$ In our patient cohort, suture line ruptures were mostly located at the distal suture line of the aortic Dacron prosthesis, but also seen proximally. A huge perigraft hematoma reaching the sternum was present infrequently, hindering immediate sternal access. These patients did not exhibit significant enlargement of the remnant aorta. The reason for suture line dehiscence was evident in only $30 \%$ of patients who presented with graft infection. These cases were particularly 
TABLE 3. Surgical redo procedures

\begin{tabular}{|c|c|c|c|c|c|c|c|c|}
\hline & Priority & Redo procedure & $\begin{array}{c}\text { Concomitant } \\
\text { procedure }\end{array}$ & $\begin{array}{c}\text { Arterial } \\
\text { cannulation }\end{array}$ & $\begin{array}{l}\text { Extracorporeal } \\
\text { circulation (min) }\end{array}$ & $\begin{array}{c}\text { Crossclamp } \\
\text { (min) }\end{array}$ & $\begin{array}{l}\text { Circulatory } \\
\text { arrest (min) }\end{array}$ & $\begin{array}{c}\text { Selective cerebral } \\
\text { perfusion (min) }\end{array}$ \\
\hline 1 & Emergency & Bioconduit & & Femoral & 292 & 125 & 0 & 0 \\
\hline 2 & Urgent & AAR & & femoral & 247 & 97 & 0 & 0 \\
\hline 3 & Urgent & $\mathrm{AAR}+\mathrm{ArchR}+\mathrm{ET}$ & $\begin{array}{l}\text { Stent in descending } \\
\text { aorta }\end{array}$ & Subclavian & 212 & 169 & 70 & 32 \\
\hline 4 & Urgent & $\begin{array}{l}\text { Homograft root }+ \text { AAR }+ \\
\text { ArchR }\end{array}$ & CABG & Femoral & 297 & 185 & 65 & 53 \\
\hline 5 & Urgent & $\mathrm{AAR}+\mathrm{ArchR}$ & & Femoral & 149 & 89 & 37 & 27 \\
\hline 6 & Elective & $\mathrm{MCT}+\mathrm{ArchR}$ & & Aorta & 207 & 151 & 66 & 47 \\
\hline 7 & Elective & HAR & & Aorta & 99 & 56 & 32 & 23 \\
\hline 8 & Urgent & $\mathrm{AAR}+\mathrm{FET}$ & & Aorta & 242 & 215 & 103 & 99 \\
\hline 9 & Elective & FET & & Subclavian & 144 & 80 & 80 & 57 \\
\hline 10 & Elective & Patch repair distal arch & $\begin{array}{l}\text { Stent in descending } \\
\text { aorta }\end{array}$ & Aorta & 184 & 68 & 68 & 41 \\
\hline 11 & Emergency & MCT & CABG & Femoral & 309 & 140 & 25 & 20 \\
\hline 12 & Elective & $\mathrm{AAR}+\mathrm{FET}$ & & Aorta & 179 & 128 & 86 & 74 \\
\hline 13 & Emergency & $\begin{array}{l}\text { 1. } \mathrm{AAR}+\mathrm{Arch} \\
\text { 2. AAR + Arch }\end{array}$ & & $\begin{array}{l}\text { Femoral } \\
\text { femoral }\end{array}$ & 160 & 65 & 65 & 26 \\
\hline 14 & Elective & AAR & & Subclavian & 97 & 66 & 0 & 0 \\
\hline 15 & Urgent & AAR & & Aorta & 61 & 27 & 0 & 0 \\
\hline 16 & Emergency & $\mathrm{AAR}+\mathrm{FET}$ & & Femoral & 186 & 186 & 90 & 78 \\
\hline 17 & Elective & $\mathrm{AAR}+\mathrm{HAR}$ & & Subclavian & 169 & 77 & 37 & 20 \\
\hline 18 & Emergency & $\mathrm{AAR}+\mathrm{HAR}$ & & Femoral & 166 & 93 & 47 & 40 \\
\hline 19 & Elective & MCT & CABG & Aorta & 301 & 117 & 45 & 21 \\
\hline 20 & Urgent & $\mathrm{AVR}+\mathrm{AAR}+\mathrm{HAR}$ & & Subclavian & 385 & 203 & 33 & 33 \\
\hline 21 & Urgent & HAR & & Subclavian & 72 & 36 & 19 & 17 \\
\hline 22 & Elective & $\mathrm{AAR}+\mathrm{FET}$ & & Subclavian & 206 & 110 & 85 & 80 \\
\hline 23 & Elective & $\mathrm{AAR}+\mathrm{FET}$ & & Subclavian & 201 & 117 & 85 & 78 \\
\hline
\end{tabular}

$A A R$, Ascending aorta replacement; $A V R$, aortic valve replacement; $M C T$, mechanical valved conduit; $H A R$, hemiarch replacement; $A r c h R$, total aortic arch replacement; $E T$, elephant trunk; $F E T$, frozen elephant trunk (Jotec Evita open); $C A B G$, coronary artery bypass grafting.

challenging because the extent of infection could not be adequately judged during surgery, and thus complete eradication of infection was virtually impossible. (3) An aortic root problem was far less common. Isolated aortic valve replacement or implantation of a mechanical or biological valved conduit was performed in only $26 \%$ of cases. Half of the patients had graft infection, and an involvement of the native aortic valve was evident or assumed. Our overall reoperative incidence of $10.0 \%$ was comparable to that of Geirsson and colleagues, ${ }^{6}$ who reported on aortic reoperations in $10.8 \%$ cases after type A dissection.

The indication for redo surgery was established in case of progressive aortic enlargement, development of a false aneurysm/rupture, proven graft infection, or aortic valve incompetence, but not in the mere presence of a persisting false lumen in the aortic arch. Because these surgical procedures are considered to be high risk and a last resort, there are no general indications for redo surgery with regard to the aneurysmal growth. Although we establish the indication for redo surgery if the maximal diameter exceeds 5.5 $\mathrm{cm}$ in the ascending aorta and $6 \mathrm{~cm}$ in the descending aorta, others wait for greater than $6.5 \mathrm{~cm}$ or a yearly growth rate of greater than $0.75 \mathrm{~cm}^{6}$
Only 3 patients were unsuitable candidates for redo surgery because of advanced age or comorbidity. Of note, all are still alive at a follow-up of 2 years. The assumed considerable risk for the second surgical procedure allowed us to choose a presumed safe surgical technique. Accordingly, most patients were connected to the aortic line of the extracorporeal circulation via the right subclavian or a femoral artery before sternotomy. After right atrial cannulation for the venous line and initiation of extracorporeal circulation, the patients were cooled to $20^{\circ} \mathrm{C}$. Aortic arch surgery was performed with continuous cerebral perfusion via the subclavian artery and clamping the brachiocephalic trunk and left carotid artery. Additional perfusion via the left carotid artery was only initiated when the nearinfrared spectroscopy system suspected left-sided hypoperfusion of the brain. If the subclavian access was not used, balloon catheters were placed into the orifices of the head vessels. We did not see the necessity of carotid cannulation and perfusion, as has been proposed by Mohammadi and colleagues. ${ }^{10}$ They reported a rupture rate of $32 \%$ during sternum reentry and a mortality rate of $17.2 \%$. Instead of such an extensive safety net, we rely on bifemoral cannulation and hypothermia in respective patients. We noted 

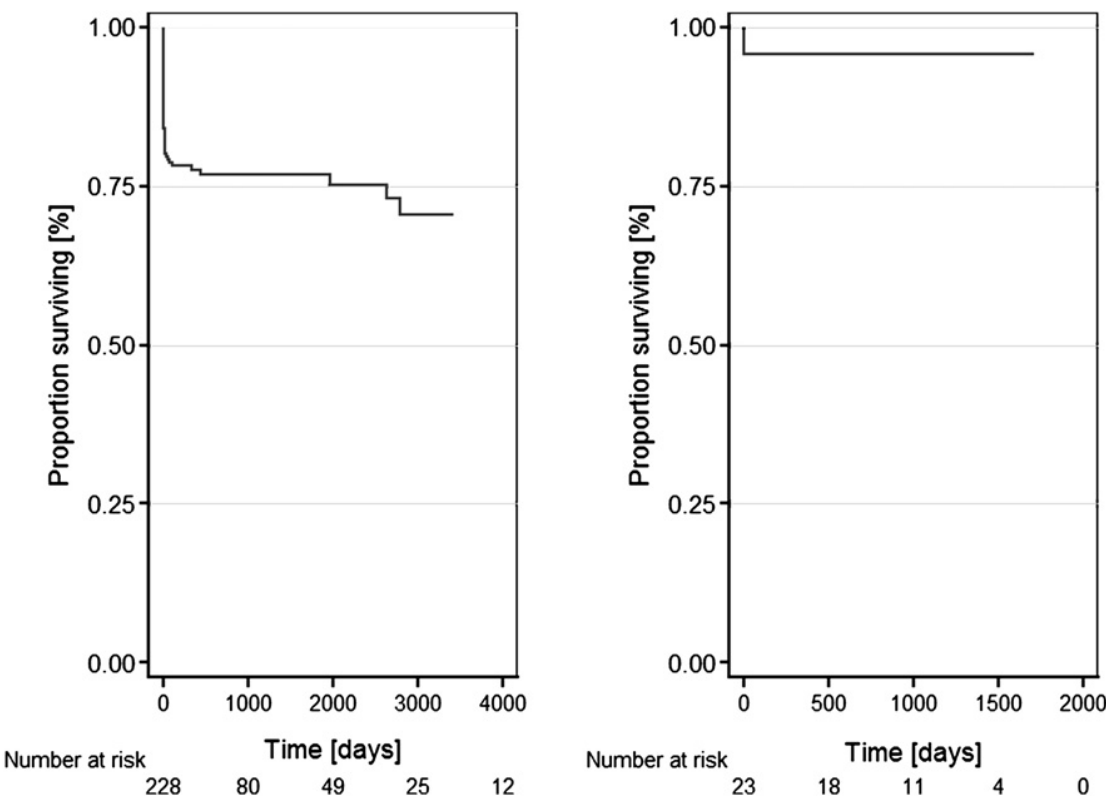

FIGURE 2. Kaplan-Meier survival after primary surgery for acute type A dissection $(n=228)$ and after late redo surgery $(n=23)$.

reentry ruptures in only $13 \%$ of patients and had a low mortality rate.

The false lumina of the descending aorta and the cerebral vessel island were obliterated with a running suture before implantation of a tubular prosthesis or stent graft. More recently, hybrid stent graft placement (frozen elephant trunk) has become the favorite technique. This surgical procedure unites conventional aortic arch replacement with an

TABLE 4. Postoperative course

\begin{tabular}{|c|c|c|c|c|c|c|c|c|c|c|}
\hline & Survival & $\begin{array}{l}\text { Drainage } \\
\text { loss }(\mathrm{mL})\end{array}$ & $\begin{array}{c}\text { Revision for } \\
\text { bleeding }\end{array}$ & $\begin{array}{l}\text { Intubation } \\
\text { (h) }\end{array}$ & $\begin{array}{c}\text { Cerebrovascular } \\
\text { accident }\end{array}$ & $\begin{array}{l}\text { Vocal } \\
\text { cord } \\
\text { injury }\end{array}$ & $\begin{array}{l}\text { Intensive } \\
\text { care unit } \\
\text { stay (d) }\end{array}$ & $\begin{array}{l}\text { Hospital } \\
\text { stay (d) }\end{array}$ & $\begin{array}{l}\text { NYHA at } \\
\text { discharge }\end{array}$ & Further interventions \\
\hline 1 & Yes & 1500 & & 30 & & & 7 & 30 & I & \\
\hline 2 & Yes & 100 & & 36 & & & 5 & 50 & I-II & \\
\hline 3 & Yes & 1500 & & 120 & & & 12 & 24 & I & \\
\hline 4 & Yes & 900 & & 24 & & & 4 & 14 & II & Coronary angiography \\
\hline 5 & Yes & 600 & & 9 & & & 2 & 15 & I & \\
\hline 6 & Yes & 970 & & 192 & & & 16 & 31 & I & \\
\hline 7 & Yes & 900 & & 12 & & & 2 & 8 & I & \\
\hline 8 & Yes & 3570 & $2 \times$ & 240 & & Yes & 16 & 39 & I & $\begin{array}{l}\text { Resternotomy (day } 14 \text { to late } \\
\text { tamponade) }\end{array}$ \\
\hline 9 & Yes & 2200 & $1 \times$ & 1296 & & Yes & 53 & 57 & III & \\
\hline 10 & Yes & 3940 & $1 \times$ & 168 & & Yes & 9 & 17 & I & Stent re-replacement \\
\hline 11 & Yes & 130 & & 41 & & & 4 & 12 & I & \\
\hline 12 & Yes & 1700 & & 20 & & & 4 & 15 & I & \\
\hline 13 & Yes & 400 & & 10 & & & 3 & 8 & I & \\
\hline 14 & Yes & 550 & & 8 & & & 2 & 15 & I & \\
\hline 15 & Yes & 650 & & 15 & & & 2 & 39 & I & \\
\hline 16 & Yes & 600 & & 70 & & & 2 & 25 & III-IV & Coronary angiography \\
\hline 17 & Yes & 1650 & & 4 & & & 7 & 25 & I-II & \\
\hline 18 & Yes & 1000 & & 33 & & & 3 & 16 & I & \\
\hline 19 & Yes & 1030 & & 44 & & & 5 & 5 & $\mathrm{n} / \mathrm{a}$ & ECMO for low output \\
\hline 20 & Yes & 2000 & $1 \times$ & 96 & & & 8 & 15 & I & \\
\hline 21 & Yes & 300 & & 145 & $1 \times$ & Yes & 11 & 13 & II & \\
\hline 22 & Yes & 600 & & 25 & & Yes & 5 & 9 & I & \\
\hline 23 & Yes & 3895 & $1 \times$ & 119 & & Yes & 8 & 15 & I & \\
\hline
\end{tabular}

NYHA, New York Heart Association; ECMO, extracorporeal membrane oxygenation; $n / a$, not available. 


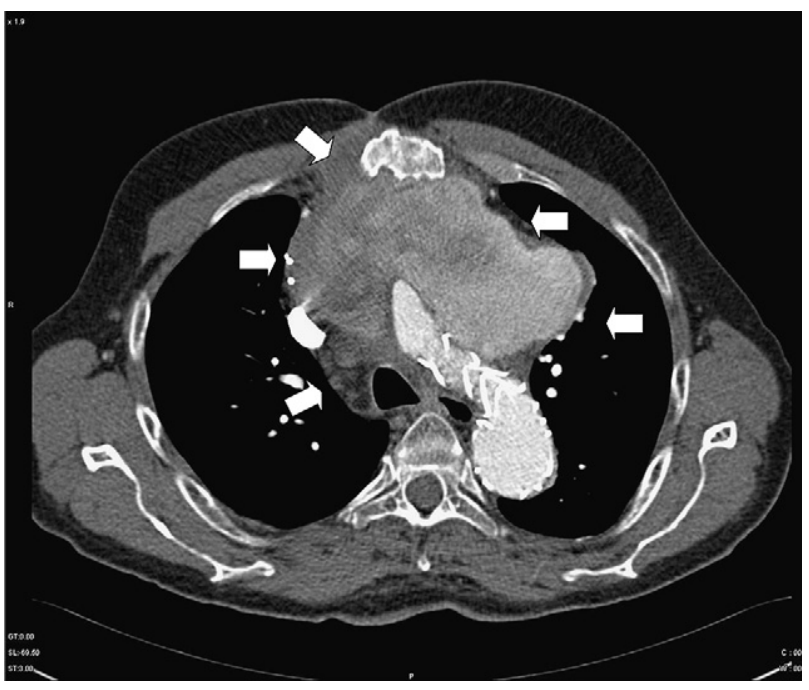

FIGURE 3. Aortic rupture after separate replacement of the aortic valve and ascending aorta and stenting of the descending aorta (patient 13).

antegrade stent placement into the descending aorta. The true lumen is stabilized with the covered stent while the false lumen is proximally occluded and progressively obliterated. It further enables the interventionalist to connect further endovascular stents in the descending aorta. Tsagakis and colleagues ${ }^{9}$ confirm the superiority of this technique in a newly generated international registry with a thrombosis rate of the false lumen of $93 \%$ (complete $76 \%$ ). Standard total arch replacement was not considered an option because it leaves the descending aorta untreated, unless there is no reentry or an elephant trunk procedure is added. A further option could be routine stent graft placement to cover the distal reentry site, but this was not our policy.

All redo procedures were straightforward without significant technical difficulties. The outcome in this small series was good and compares favorably to the sparse literature, in which mortality rates up to $41 \%$ have been reported. ${ }^{6,9,10,12,13}$ In view of the comorbidities of our patient cohort, we therefore continue to advocate a simple and fast emergency operation in case of acute type A dissection, that is, resection of the intimal tear and replacement of the ascending aorta with an open distal anastomosis. Total arch repair remains reserved for patients with extensive aortic arch pathologies. The stent graft proved to be a highly effective and elegant technique for the redo procedures because it also offered a safe way to place further endoluminal stents into the descending aorta. In contrast, conventional elephant trunk prosthesis did not always allow a secondary endoluminal stent to be securely anchored.

Our late findings after aortic surgery for acute type A dissection underline the importance of a long-term follow-up, certainly well more than 5 years after surgery, because the average time interval for redo surgery was approximately
6 years after the initial procedure. This is especially true for patients with Marfan syndrome..$^{10,14,15}$ Similar observations have been made by Mohammadi and colleagues, ${ }^{10}$ Bachet and colleagues, ${ }^{12}$ and Pugliese and colleagues, ${ }^{16}$ who reported time intervals between repair and reoperation of more than 60 months. A yearly imaging of the aorta is warranted to detect these complications early, by $\mathrm{CT}$ or magnetic resonance imaging. The problem of persisting dissection in the aortic arch stimulates the discussion on whether the aortic arch should always be replaced during the initial procedure. Protagonists point out similar mortality rates with aggressive surgical approaches. ${ }^{17-19}$ We and others observed a low reoperative rate and do not recommend the latter, but we want to emphasize the importance of obliterating the false lumen of the aortic arch, for example, with tissue glue or suture. ${ }^{4,6} \mathrm{We}$ observed no aortic root necrosis due to inadequate application of GRFG glue. ${ }^{20}$ However, because a significant number of patients were lost to follow-up after the initial repair of acute type A dissection, our results may be influenced by underreporting the need for a second surgical procedure.

\section{CONCLUSIONS}

Persistent dissection is an ongoing disease despite proximal repair, potentially mandating a subsequent operation. Therefore, a long-term follow-up is obligatory. Whether a more aggressive approach during the initial procedure (ie, arch replacement) is indicated to prevent late complications is still under debate, particularly considering that this complication does not develop in all patients. The operative strategy should be based on individual findings, and the extent of the primary repair must be weighed against the operative risk. When a second operation is necessary in patients, our data indicate that this can be safely done.

\section{References}

1. Myrmel T, Lai DT, Miller DC. Can the principles of evidence-based medicine be applied to the treatment of aortic dissections? Eur J Cardiothorac Surg. 2004;25: 236-45.

2. Feldman M, Shah M, Elefteriades JA. Medical management of acute type A aortic dissection. Ann Thorac Cardiovasc Surg. 2009;15:286-93.

3. Weigang E, Conzelmann LO, Kallenbach K, et al. German registry for acute aortic dissection type A (GERAADA)-lessons learned from the registry. Thorac Cardiovasc Surg. 2010;58:154-8.

4. Halstead JC, Meier M, Etz C, et al. The fate of the distal aorta after repair of acute type A aortic dissection. J Thorac Cardiovasc Surg. 2007;133:127-35.

5. Tsai TT, Evangelista A, Nienaber CA, et al. Long-term survival in patients presenting with type A acute aortic dissection: insights from the International Registry of Acute Aortic Dissection (IRAD). Circulation. 2006;114:I350-6.

6. Geirsson A, Bavaria JE, Swarr D, et al. Fate of the residual distal and proximal aorta after acute type a dissection repair using a contemporary surgical reconstruction algorithm. Ann Thorac Surg. 2007;84:1955-64.

7. Zierer A, Voeller RK, Hill KE, et al. Aortic enlargement and late reoperation after repair of acute type A aortic dissection. Ann Thorac Surg. 2007;84:479-87.

8. Jakob H, Tsagakis K, Tossios $\mathrm{P}$, et al. Combining classic surgery with descending stent grafting for acute DeBakey type I dissection. Ann Thorac Surg. 2008;86: 95-101.

9. Tsagakis K, Pacini D, Di Bartolomeo R, et al. Arch replacement and downstream stent grafting in complex aortic dissection: first results of an international registry. Eur J Cardiothorac Surg. 2011;39:87-94. Epub 2010 Jun 2. 
10. Mohammadi S, Bonnet N, Leprince P, et al. Reoperation for false aneurysm of the ascending aorta after its prosthetic replacement: surgical strategy. Ann Thorac Surg. 2005;79:147-52

11. Kazui T, Yamashita K, Terada H, et al. Late reoperation for proximal aortic and arch complications after previous composite graft replacement in Marfan patients. Ann Thorac Surg. 2003;76:1203-8.

12. Bachet JE, Termignon JL, Dreyfus G, et al. Aortic dissection. Prevalence, cause, and results of late reoperations. J Thorac Cardiovasc Surg. 1994;108:199-206.

13. Razzouk A, Gundry S, Wang N, et al. Pseudoaneurysms of the aorta after cardiac surgery or chest trauma. Am Surg. 1993;59:818-23.

14. Carrel T, Beyeler L, Schnyder A, et al. Reoperations and late adverse outcome in Marfan patients following cardiovascular surgery. Eur J Cardiothorac Sur. 2004; 25:671-5.

15. Stevens LM, Madsen JC, Isselbacher EM, et al. Surgical management and longterm outcomes for acute ascending aortic dissection. J Thorac Cardiovasc Surg. 2009;138:1349-57. e1.
16. Pugliese P, Pessotto R, Santini F, et al. Risk of late reoperations in patients with acute type A aortic dissection: impact of a more radical surgical approach. Eur J Cardiothorac Surg. 1998;13:576-81.

17. Moon MR, Sundt TM 3rd, Pasque MK, et al. Does the extent of proximal or distal resection influence outcome for type A dissections? Ann Thorac Surg. 2001;71: 1244-50.

18. Kazui T, Yamashita K, Washiyama N, et al. Impact of an aggressive surgical approach on surgical outcome in type A aortic dissection. Ann Thorac Surg. 2002 74:S1844-63.

19. Kirsch M, Soustelle C, Houel R, et al. Risk factor analysis for proximal and dista reoperations after surgery for acute type A aortic dissection. J Thorac Cardiovasc Surg. 2002;123:318-25.

20. Suzuki S, Imoto K, Uchida K, Takanashi Y. Aortic root necrosis after surgical treatment using gelatin-resorcinol-formaldehyde (GRF) glue in patient with acute type A aortic dissection. Ann Thorac Cardiovasc Surg. 2006;12: 333-40. 